\title{
Perspective Taking as a Means of Reducing Negative Stereotyping of Individuals Who Speak English as a Second Language ${ }^{1}$
}

\author{
JAMES M. WEYANT ${ }^{2}$ \\ University of San Diego
}

\begin{abstract}
As a test of the hypothesis that perspective taking reduces stereotyping of individuals who speak English as a second language, 160 college students participated in a $2 \times 2$ factorial experiment. Participants heard an audio recording of either a native or non-native speaker of English. Then, they wrote a paragraph about the speaker either with instructions to take the speaker's perspective or with no perspectivetaking instructions. Finally, they rated the speaker on characteristics related to ability and accomplishment. Overall, the participants rated the native speaker of English more highly than the non-native speaker. However, supporting the hypothesis, participants instructed to take the perspective of the non-native speaker rated her more highly than did participants not instructed to take her perspective.
\end{abstract}

In the movie $A$ Walk in the Clouds (Zucker \& Arau, 1995), a highly successful but nevertheless frustrated Mexican American man asserts "Just because I speak with an accent doesn't mean I think with an accent." The source of the man's frustration no doubt is shared by millions of individuals who immigrate to lands where they must communicate in what for them is a second language. Unfortunately, it seems that rather than being impressed by the resourcefulness it takes to function with a second language, a foreign accent often may be taken as a sign of muddled thinking.

We might expect that the often observed inclination to view members of out-groups negatively (Brewer, 1979; Gaertner, Mann, Murrell, \& Dovidio, 1989; Tajfel, Billig, Bundy, \& Flament, 1971) may apply to those who speak with a foreign accent. Lending support to this notion, studies have shown that non-native speakers of a language are viewed as having less status than are native speakers (Nesdale \& Rooney, 1990; Nesdale \& Rooney, 1996; Ryan \& Carranza, 1975; Ryan \& Sebastian, 1980). In these studies, status

${ }^{1}$ The author thanks Virginia Lewis and Eugenia Navas for providing the voices on the stimulus recordings; AnyMary Weyant for writing the script for the stimulus recordings; and Alison Herdocia, Janae Draper, and Lindsy Giebel for serving as experimenters.

${ }^{2}$ Correspondence concerning this article should be addressed to James M. Weyant, Department of Psychology, University of San Diego, 5998 Alcala Park, San Diego, CA 92110. E-mail: jweyant@SanDiego.edu

Journal of Applied Social Psychology, 2007, 37, 4, pp. 703-716.

(C) 2007 Copyright the Authors

Journal compilation (C) 2007 Blackwell Publishing, Inc. 
was a composite measure that, in addition to perceptions of factors such as wealth and success, included ratings of perceived intelligence and education. In addition, evidence has indicated that individuals with a foreign accent may be discriminated against when they apply for high-status jobs (Kalin \& Rayko, 1978).

Although it may be true that speakers with foreign accents are likely to be negatively stereotyped, there may be exceptions. For example, one study showed that in the United States, individuals who spoke English with a British accent were rated as having higher status than were individuals who spoke "American" English (Stewart, Ryan, \& Giles, 1985). However, ratings of individuals who speak English with a Spanish accent have consistently shown that such individuals are negatively stereotyped (Ryan \& Carranza, 1975; Ryan, Carranza, \& Moffie, 1977; Ryan \& Sebastian, 1980). To help combat such persistent biases, the current study is designed to explore the possibility that perspective taking can reduce stereotyping of individuals who speak English with a Spanish accent.

Perspective taking involves attempts to imagine oneself in the shoes of another and may entail efforts to think from the other person's point of view, to envision oneself in the other person's circumstances, and to feel what the other person is feeling. Prior research has shown that perspective taking induces thoughts, feelings, and actions that are kindly toward people who are contemplated in this fashion (Batson et al., 1997; Eisenberg, Carlo, Murphy, \& Van Court, 1995; Eisenberg, Zhou, \& Koller, 2001; Toi \& Batson, 1982; Underwood \& Moore, 1982). These results may occur by arousing empathy for the other person (Batson et al., 1997), by reducing perceived differences between the self and other (Galinsky \& Moskowitz, 2000), or perhaps a combination of these two mechanisms.

Pertinent to the current study, research has shown that taking the perspective of a member of a stigmatized group can reduce negative attitudes that otherwise might be held about members of that group. In one study, Batson et al. (1997) asked college students to listen to an audio recording of a woman talking about her personal ordeal of living with the knowledge that she is HIV-positive and of dreading the time when her condition will develop into AIDS. Before listening to the recording, some participants were instructed to take the speaker's perspective by imagining how she was feeling about her experience, whereas other participants were instructed to remain objective and to avoid getting "caught up" in how the speaker was feeling.

As expected, students who were instructed to take the speaker's perspective later reported more empathy and more favorable attitudes toward people with AIDS than did students who were instructed to remain objective. Using the same perspective-taking and objectivity instructions, Vescio, Sechrist, 
and Paolucci (2003) asked White college students to listen to an African American student describe how he, as a Black man, experienced problems adjusting to college life. Paralleling the main findings of Batson et al.'s (1997) study, students who were instructed to take the speaker's perspective later reported more empathy and more favorable attitudes toward African Americans than did students who were instructed to remain objective.

Using different procedures, Galinsky and colleagues (Galinsky \& $\mathrm{Ku}$, 2004; Galinsky \& Moskowitz, 2000) also found that perspective taking reduced negative stereotyping of an often stigmatized group. In their experiments, college students viewed a picture of an elderly man and were asked to write an essay about a typical day in the man's life. Before writing the essay, half of the participants received perspective-taking instructions that directed them to put themselves in the shoes of the man depicted in the picture and to write the essay as if they were that man. The other half of the participants, serving as controls, received no perspective-taking instructions. When they were asked later to rate the elderly on a number of traits, participants in the perspective-taking condition gave more favorable ratings than did those in the control condition.

The purpose of the present study is to test whether a perspective-taking exercise can be applied successfully to the goal of reducing stereotypical perceptions of an individual who speaks English as a second language. To test this possibility, college students first listened to an audio recording in which a woman, speaking in English, described early childhood experiences. Although the content of the recordings was the same in all cases, half of the participants heard a native speaker of English, and the other half heard a speaker whose first language is Spanish. Using a modified version of Galinsky and Moskowitz's (2000) perspective-taking manipulation, the students next wrote a paragraph about what they thought a typical day in the life of the speaker might be like. Students in the perspective-taking condition were instructed to write as if they were the speaker, whereas students in the control condition were given no special instructions about what perspective to take. After writing the essay, students rated the speaker on a number of bipolar scales related to abilities and accomplishments.

Following from earlier work demonstrating negative stereotyping of outgroups (including those who speak with a foreign accent), it is predicted that the speaker with the Spanish accent will be rated as less able and less accomplished than will the native speaker of English. Moreover, based on prior research demonstrating that perspective taking can reduce negative stereotyping of stigmatized groups, it is also predicted that the inclination to rate the speaker with an accent less favorably than the native speaker will be less pronounced, or may not occur at all, after participants write about her from her own perspective. 


\section{Method}

Design

The study design was a $2 \times 2$ independent groups factorial experiment. One factor was the first language of the speaker (English or Spanish). The other factor was whether or not participants were explicitly instructed to take the speaker's perspective.

\section{Participants}

Participants were 160 students (118 female, 42 male) who participated in partial fulfillment of a course requirement in their introductory psychology classes. Participants ranged in age from 17 years to 29 years, and most (89\%) spoke English as a first language. Among the non-native speakers of English, 10 spoke Spanish as a first language and the other 8 spoke a variety of other first languages.

Participants typically were run in groups of 4; and within each group, they were randomly assigned to the four experimental conditions. Sessions with fewer than 4 participants were balanced with other partial sessions to achieve a sample size of 40 per condition. Given the study's focus on a stimulus person whose first language is Spanish, it is important to note that the 10 participants who spoke Spanish as a first language were well dispersed among the four conditions, with either 2 or 3 per condition.

\section{Stimulus Recordings}

Using one of four personal compact-disk (CD) players, each equipped with headphones, participants listened to an audio recording of one of two women speaking in English. Both speakers read from the same script. Thus, the content of the two recordings was the same. However, one of the women spoke English as a first language, whereas the other spoke Spanish as a first language. Both women speak English fluently and can be understood readily, but the one who speaks English as a second language does so with a readily recognizable accent. Before they were recorded, the women rehearsed the script and were coached to read it in a manner that was similar in pace, mood, and clarity.

The script was designed to fit plausibly with participants' task of making interpersonal judgments in a psychology experiment. Written in the first person, it relates a story about early childhood experiences and family rela- 
tionships. A prominent theme is that the speaker worshipped her father and strove for his approval, even though he was so involved in his work that he had little time for family matters. In contrast, the speaker's grandfather was depicted as loving and nurturing, and her mother was described as overly controlling.

The recordings were digitally produced on a computer and then burned onto CDs. This technique led to high quality recordings. To accommodate running 4 participants per condition, four copies of the recordings were produced: two of the native English speaker, and two of the native Spanish speaker.

\section{Procedure}

Participants signed up for a study of "how people perceive others." Upon their arrival at the laboratory, participants were greeted by a female undergraduate who served as the experimenter. Three female students served as experimenters, each one conducting approximately one third of the experimental sessions.

There were 4 participants scheduled for each session. The experimenter directed each participant to find a place to sit at a long table. A consent form, a response booklet, and a personal CD player were on the table at each of the four places. Unknown to participants, two of the CD players were loaded with recordings of the native English speaker, and two players were loaded with recordings of the native Spanish speaker. Also unknown to participants, within each of the first-language conditions, one response booklet included perspective-taking instructions, while the other did not. Thus, each of the four seats constituted one of four experimental conditions in the $2 \times 2$ design. For each session, the experimenter randomly assigned the experimental conditions to seating locations, with the restriction that all four conditions were set up for each session.

After participants were seated, the experimenter asked them to read and sign the consent form. The form revealed that they were (a) to listen to a brief audio recording of a speaker talking about her childhood experiences; (b) to write a paragraph about what they thought a typical day in the life of the speaker might be like; and (c) to complete a questionnaire indicating their opinions of the speaker. All participants signed the consent form.

After participants signed the consent form, the experimenter asked them to read the instructions on the cover sheet of the response booklet. The instructions directed participants first to listen to the recording, then to provide impressions of the speaker on the next two pages of the response booklet, and finally to provide information about themselves on the last 
page of the booklet. Before participants proceeded with these tasks, the experimenter asked if there were any questions, directed participants to use the earphones, and helped anyone needing assistance in using the CD player.

After listening to the recordings, participants turned to the second page of the response booklet. Instructions on that page - which was entitled "A Day in the Life"- directed participants to write a paragraph about what they thought a day in the life of the speaker might be like, including things she would be likely to do and thoughts she would be likely to have. Based on Galinsky and Moskowitz's (2000) perspective-taking instructions, in half of the cases, the instructions went on to request that participants try to view things from the perspective of the speaker as if they were "walking in her shoes." To bolster this manipulation, the instructions also directed participants to write in the first person; for example, using "I" and "me" when referring to she or her. The other half of participants were given no perspective-taking instructions.

After writing the "day in the life" paragraphs, participants turned to the next page of the response booklet. Instructions on that page-which was entitled "Impressions"- directed participants to indicate their impressions of the speaker by placing check marks on 7-point bipolar scales. Each scale was anchored at each end by a bipolar trait, with seven dashes in between. Placement of the positive or negative side of the scale on the right or the left was counterbalanced to minimize response bias. However, in order to facilitate interpretation of the results, the data were coded on a 7-point scale ranging from 1 to 7 such that high scores always reflect favorable ratings.

Items that constitute the dependent measure for the study were interspersed with filler items. These dependent measures center on ratings of the speaker's ability (i.e., unintelligent-intelligent, imperceptive-perceptive, dullbright, inept-capable, and competent-incompetent) and her level of accomplishment (i.e., unsuccessful-successful, ignorant-knowledgeable, and poorly educated-well educated).

After they completed the rating scales, participants turned to the final page of the response booklet, where they provided information about themselves, including gender, age, and first language. When all participants in a session completed their response booklets, the experimenter asked if they had any questions, debriefed them with regard to the true purpose of the study, thanked them for participating, and asked them not to divulge information to anyone who might participate later. 


\section{Results}

\section{Manipulation Check}

In the perspective-taking conditions, participants were asked to write about a day in the life of the speaker as if they were the speaker and were specifically instructed to do so by using first-person pronouns. In comparison conditions, participants were asked to write about a day in the life of the speaker without the perspective-taking instructions. Word counts of the paragraphs show that participants followed the instructions. Out of all the words written by participants in the perspective-taking conditions, $14.7 \%$ were first-person pronouns used as if the participant were the speaker. No participant in these conditions used less than $8.0 \%$ of his or her total words in this manner. In the comparison conditions, only 2 participants used first-person pronouns as if they were the speaker, and each of these participants did so only once. For both of these participants, the one personal pronoun that they used constituted less than $1.0 \%$ of the total words that they wrote. Overall, out of all the words written in the comparison conditions, only $0.1 \%$ were first-person pronouns used as if the participant were the speaker.

\section{Multivariate Tests of Main Hypotheses}

The effects of the speaker's first language, perspective taking, and the interaction of these two factors were subjected to a two-way MANOVA. The dependent variables for the analysis were the eight rating scales designed to measure perceptions of the speakers' ability and accomplishments. Consistent with the hypotheses, the main effect of the speaker's first language was statistically significant, $F(8,149)=6.01, p<.0005$; and the interaction of speaker's first language and perspective taking was statistically significant, $F(8,149)=2.86, p=.005$. The main effect of perspective taking was statistically significant also, $F(8,149)=2.08, p=.04$.

\section{Univariate Tests of Main Hypotheses}

Consistent with the hypotheses, univariate ANOVAs indicate that on all measures, the native speaker of English was rated more highly than was the non-native speaker. That is, compared to the non-native speaker, the native speaker was rated as more intelligent, $F(1,156)=28.15, p<.0005$; more knowledgeable, $F(1,156)=13.74, p<.0005$; brighter, $F(1,156)=17.82$, 
$p<.0005$; more competent, $F(1,156)=19.48, p<.0005$; more successful, $F(1,156)=6.50, p=.012$; more perceptive, $F(1,156)=7.37, p=.007$; more capable, $F(1,156)=12.13, p=.001$; and more educated, $F(1,156)=30.14$, $p<.0005$.

The univariate ANOVAs also indicate that, on seven of eight measures, taking the speaker's perspective led to higher ratings of her abilities and accomplishments. Compared to participants who were in the condition that did not involve perspective taking, those who were instructed to take the speaker's perspective rated her as more intelligent, $F(1,156)=6.32$, $p=.013$; more knowledgeable, $F(1,156)=5.99, p=.015$; brighter, $F(1,156)$ $=6.70, p=.011$; more competent, $F(1,156)=8.66, p=.004$; more perceptive, $F(1,156)=4.88, p=.029$; more capable, $F(1,156)=9.77, p=.001$; and more educated, $F(1,156)=7.34, p=.007$. The only measures that did not produce a main effect of perspective taking was perceptions of the speaker's level of success, $F(1,156)=2.60, p=.11$.

The main hypothesis of the current study is that perspective taking can reduce negative stereotyping of individuals who speak English as a second language. Thus, it was predicted that the speaker's first language and perspective taking would interact. Specifically, it was expected that whereas perspective taking would have little or no effect on ratings of the abilities and accomplishments of the native speaker of English, it would elevate ratings given to the non-native speaker. The univariate ANOVAs indicated that the expected interaction occurred on five of the eight dependent measures. ${ }^{3}$ As expected, the speaker's first language significantly interacted with perspective taking on ratings of the speaker's intelligence, $F(1,156)=4.58, p=.03$; competence, $F(1,156)=7.61, p=.007$; perceptiveness, $F(1,156)=4.88, p=.03$; capability, $F(1,156)=20.74, p<.0005$; and level of education, $F(1$, $156)=5.26, p=.02$. Means relevant to these interactions are presented in Table 1. Although mean differences were in the expected pattern, there were no significant interactions on ratings of the speaker's knowledge, $F(1$, $156)=2.16, p=.14$; brightness, $F(1,156)=1.50, p=.22$; and level of success, $F(1,156)=0.65, p=.42$.

Simple-effects ANOVAs on the dependent measures that had shown significant interactions indicate clear support for the main hypothesis. Perspective taking significantly increased ratings of the non-native speaker's intelligence, $F(1,156)=10.83, p=.001$; but had no significant effect on ratings of the native speaker's intelligence, $F(1,156)=0.07, p=.79$. Perspective taking significantly increased ratings of the non-native speaker's

${ }^{3} \mathrm{~A}$ parallel set of analyses run on the data of only English-speaking participants produced exactly the same pattern of significant multivariate and univariate main effects and interactions as those reported in the text of this report. 
Table 1

Ratings of Speaker's Traits by Condition

\begin{tabular}{lccccc}
\hline & \multicolumn{2}{c}{$\begin{array}{c}\text { Took speaker's } \\
\text { perspective }\end{array}$} & & \multicolumn{2}{c}{$\begin{array}{c}\text { Did not take speaker's } \\
\text { perspective }\end{array}$} \\
\cline { 2 - 3 } \cline { 5 - 6 } & $\begin{array}{c}\text { Native } \\
\text { speaker }\end{array}$ & $\begin{array}{c}\text { Non-native } \\
\text { speaker }\end{array}$ & & $\begin{array}{c}\text { Native } \\
\text { speaker }\end{array}$ & $\begin{array}{c}\text { Non-native } \\
\text { speaker }\end{array}$ \\
\hline Intelligent & $6.02_{\mathrm{a}}$ & $5.60_{\mathrm{a}}$ & & $5.98_{\mathrm{a}}$ & $4.98_{\mathrm{b}}$ \\
Competent & $5.85_{\mathrm{a}}$ & $5.62_{\mathrm{a}}$ & & $5.82_{\mathrm{a}}$ & $4.85_{\mathrm{b}}$ \\
Perceptive & $5.60_{\mathrm{a}}$ & $5.50_{\mathrm{a}}$ & & $5.60_{\mathrm{a}}$ & $4.62_{\mathrm{b}}$ \\
Capable & $6.00_{\mathrm{a}}$ & $6.15_{\mathrm{a}}$ & & $6.20_{\mathrm{a}}$ & $5.08_{\mathrm{b}}$ \\
Well educated & $6.10_{\mathrm{a}}$ & $5.52_{\mathrm{a}}$ & & $6.02_{\mathrm{a}}$ & $4.62_{\mathrm{b}}$ \\
\hline
\end{tabular}

Note. Ratings were made on 7-point bipolar scales (means listed indicate degree of the trait listed). Means in the same row that do not share subscripts differ at $p<.05$ according to Tukey's honestly significant difference comparisons.

competence, $F(1,156)=16.25, p<.0005$; but had no significant effect on ratings of the native speaker's competence, $F(1,156)=0.02, p=.90$. Perspective taking significantly increased ratings of the non-native speaker's perceptiveness, $F(1,156)=9.77, p=.002$; but had no significant effect on ratings of the native speaker's perceptiveness, $F(1,156)=0.00, p=1.00$. Perspective taking significantly increased ratings of the non-native speaker's capability, $F(1,156)=29.49, p<.0005$; but had no significant effect on ratings of the native speaker's capability, $F(1,156)=1.02, p=.31$. Perspective taking significantly increased ratings of the non-native speaker's level of education, $F(1,156)=12.53, p=.001$; but had no significant effect on ratings of the native speaker's level of education, $F(1,156)=0.09, p=.77$. Indeed, as shown in Table 1, Tukey's honestly significant difference tests indicate that, for all five dependent measures that showed interactions, the mean rating of the speaker was lowest when she was a non-native speaker and when participants had not been instructed to take her perspective $(p<.05$ in all cases).

\section{Relation Between Use of First-Person Pronouns and Ratings of the Speaker}

Further support for the notion that perspective taking helps to reduce negative stereotyping is provided by an analysis of the correlation between 
use of first-person pronouns and ratings of the speaker. It was hypothesized that negative stereotyping of the non-native speaker of English would be reduced by instructing participants to write about the speaker as if they were the speaker. An index of the degree to which participants followed this instruction was obtained by first conducting word counts of the number of words written and the number of first-person pronouns used to refer to the speaker. Then, for each participant who had received the perspective-taking instructions, the percentage of total words that were first-person pronouns was calculated. These percentages then were correlated with two composite measures of ratings of the speaker.

One composite measure was the sum of the five ratings relevant to the perceived ability of the speaker (i.e., ratings of her intelligence, perceptiveness, brightness, capability, and competence). The other composite measure was the sum of the three ratings relevant to the speaker's accomplishments (i.e., ratings of her success, knowledge, and level of education). Consistent with the notion that perspective taking helps to reduce negative stereotyping, the percentages of first-person pronouns used by participants who heard the non-native speaker of English and were instructed to write as if they were the speaker were correlated positively and significantly both with the composite rating of the speaker's perceived ability $(r=.40, p=.01)$ and with the composite rating of her perceived accomplishments $(r=.44, p=.005)$. In contrast, among participants instructed to take the perspective of a native speaker of English, for whom the participants presumably would have no negative stereotype to overcome, the correlations between the percentage of first-person pronouns used and the composite measures of ability and accomplishment were not significant $(r=.02, p=.90$, and $r=.01, p=.93$, respectively).

\section{Discussion}

The main hypothesis for the current study was that perspective taking would reduce negative stereotyping of an individual who speaks English as a second language. This hypothesis was supported strongly. Whereas perspective taking had no significant effect on ratings of a native speaker of English, participants who heard a woman speaking English as a second language rated her as significantly more intelligent, competent, perceptive, capable, and well educated after they had been instructed to write about her from her own perspective than did participants who wrote about the same non-native speaker without having been instructed to take her perspective. Also consistent with the notion that perspective taking helps to reduce negative stereotyping, among participants who rated the non-native speaker of English and 
who were instructed to write a paragraph as if they were the speaker, the percentage of the total words they wrote that were first-person pronouns was correlated positively and significantly with composite measures of their ratings of the speaker's ability and accomplishments. Thus, it seems that when rating the non-native speaker of English, the extent to which participants followed perspective-taking instructions was related directly to favorableness of their perceptions of that speaker.

The manipulation of perspective taking used in the current study was a modified version of the one that Galinsky and colleagues (Galinsky \& $\mathrm{Ku}$, 2004; Galinsky \& Moskowitz, 2000) used successfully to reduce negative stereotypes after participants saw a photograph of a member of a stigmatized group (e.g., an elderly man). In their research, participants in perspectivetaking conditions were asked to write an essay about a typical day in the life of the person in the picture from that person's perspective (as if they were the person), "looking at the world through his eyes and walking through the world in his shoes" (Galinsky \& Moskowitz, 2000, p. 711). In subsequent manipulation checks, content analyses of the essays showed that over $70 \%$ of participants who were given these instructions wrote in the first person, suggesting that most of them truly were writing as if they were the person (Galinsky \& Ku, 2004).

In the present study, participants in the perspective-taking condition were instructed to write an essay about an individual "as if walking in her shoes." However, in order to bolster the manipulation, participants were explicitly instructed to "write in the first person" using personal pronouns, such as "I" and "me." This way, $100 \%$ of participants in the perspectivetaking condition wrote in the first person. Explicitly instructing participants to write in the first person nicely follows from Galinsky's theoretical notion (Galinsky \& Ku, 2004; Galinsky \& Moskowitz, 2000) that perspective taking reduces stereotyping by blurring distinctions typically made between perceptions of the self and members of an out-group. As a practical matter, applications of perspective taking that are designed to reduce stereotyping might well use explicit instructions to write about a target person in the first person.

Batson et al. (1997) also demonstrated that perspective taking can improve attitudes toward members of stigmatized groups, but for them, the key intervening mechanism is empathy. Thus, in their experiments, participants in perspective-taking conditions were instructed to imagine how a target person feels. These instructions were designed to arouse empathic feelings (e.g., sympathy, compassion), which, it was hypothesized, would move participants to feel more kindly toward members of the target's stigmatized group. Supporting this view, research has shown that instructing participants to imagine the feelings of person who is a member of a stigma- 
tized group both arouses empathic feelings for the target person and improves attitudes toward members of the target's group (Batson et al., 1997; Vescio et al., 2003). Thus, although not tested in the current study, future applications of perspective taking as a means of reducing stereotyping of individuals who speak English as a second language might well include instructions to imagine how a target person is feeling.

Another hypothesis of the current study was that, without perspectivetaking instructions, participants would rate the native speaker of English as more able and more accomplished than the non-native speaker. This hypothesis was strongly supported. However, it is possible that the differences in ratings may have been brought about by speech characteristics other than first languages. To control for this possibility, the two women were coached to read the script in a manner that, except for differences in accents, was similar. In addition, prior studies have consistently shown that ratings of individuals who speak English with a Spanish accent, as was the case in the current study, are negatively stereotyped (Ryan, \& Carranza, 1975; Ryan, Carranza, \& Moffie, 1977; Ryan \& Sebastian, 1980).

In conclusion, the current study supports the notion that perspective taking may be a fruitful approach to reducing negative stereotyping of individuals who speak with what, to the listener, may be perceived as a foreign accent. Further research, using various accents and various types of perspective-taking exercises, could help to establish the generality and limitations of this conclusion. More generally, the current study adds to the growing body of literature indicating that perspective-taking exercises can effectively reduce stereotyping of minorities and other stigmatized groups. If further research continues to support this finding, then designers of programs intended to promote appreciation of diversity might well want to consider incorporating such exercises in their programs.

\section{References}

Batson, C. D., Polycarpou, M. P., Harmon-Jones, E., Imhoff, H. J., Mitchener, E. C., Bednar, L. L., et al. (1997). Empathy and attitudes: Can feeling for a member of a stigmatized group improve feelings toward that group? Journal of Personality and Social Psychology, 72, 105-118.

Brewer, M. B. (1979). In-group bias in the minimal intergroup situation: A cognitive-motivational analysis. Psychological Bulletin, 86, 307324.

Eisenberg, N., Carlo, G., Murphy, B., \& Van Court, P. (1995). Prosocial development in late adolescence: A longitudinal study. Child Development, 66, 1179-1197. 
Eisenberg, N., Zhou, Q., \& Koller, S. (2001). Brazilian adolescents' prosocial moral judgment and behavior: Relations to sympathy, perspective taking, gender-role orientation, and demographic characteristics. Child Development, 72, 518-534.

Gaertner, S. L., Mann, J., Murrell, A. \& Dovidio, J. F. (1989). Reducing intergroup bias: The benefits of recategorization. Journal of Personality and Social Psychology, 57, 239-249.

Galinsky, A. D., \& Ku, G. (2004). The effects of perspective-taking on prejudice: The moderating role of self-evaluation. Personality and Social Psychology Bulletin, 30, 594-604.

Galinsky, A. D., \& Moskowitz, G. B. (2000). Perspective-taking: Decreasing stereotype expression, stereotype accessibility, and in-group favoritism. Journal of Personality and Social Psychology, 78, 708-724.

Kalin, R., \& Rayko, D. S. (1978). Discrimination in evaluating judgments against foreign-accented job candidates. Psychological Reports, 43, 1203 1209.

Nesdale, A. R., \& Rooney, R. (1990). Effect of children's ethnic accents on adults' evaluations and stereotyping. Australian Journal of Psychology, 42, 309-319.

Nesdale, D., \& Rooney, R. (1996). Evaluations and stereotyping of accented speakers by pre-adolescent children. Journal of Language and Social Psychology, 15, 133-154.

Ryan, E. B., \& Carranza, M. A. (1975). Evaluative reactions of adolescents toward speakers of standard English and Mexican American accented English. Journal of Personality and Social Psychology, 31, 855-863.

Ryan, E. B., Carranza, M. A., \& Moffie, R. W. (1977). Reactions toward varying degrees of accentedness in the speech of Spanish-English bilinguals. Language and Speech, 20, 267-273.

Ryan, E. B., \& Sebastian, R. J. (1980). The effects of speech style and social class background on social judgments of speakers. British Journal of Social and Clinical Psychology, 19, 229-233.

Stewart, M. A., Ryan, E. B., \& Giles, H. (1985). Accent and social class effects on status and solidarity evaluations. Personality and Social Psychology Bulletin, 11, 98-105.

Tajfel, H., Billig, M. G., Bundy, R. P., \& Flament, C. (1971). Social categorization and intergroup behavior. European Journal of Social Psychology, $1,149-178$.

Toi, M., \& Batson, C. D. (1982). More evidence that empathy is a source of altruistic motivation. Journal of Personality and Social Psychology, 43, 281-292.

Underwood, B., \& Moore, B. (1982). Perspective-taking and altruism. Psychological Bulletin, 91, 143-173. 
Vescio, T. K., Sechrist, G. B., \& Paolucci, M. P. (2003). Perspective taking and prejudice reduction: The mediational role of empathy arousal and situational attributions. European Journal of Social Psychology, 33, 455472.

Zucker, J. (Producer), \& Arau, A. (Director). (1995). A walk in the clouds [Motion picture]. Los Angeles, CA: $20^{\text {th }}$ Century Fox. 